\title{
Prevalence and associated factors of depression among tuberculosis patients in Eastern Ethiopia
}

Tamirat Tesfaye Dasa ${ }^{1 *}$, Aklilu Abrham Roba ${ }^{1}$, Fitsum Weldegebreal ${ }^{1}$, Frehiwot Mesfin ${ }^{1}$, Abiyot Asfaw ${ }^{1}$, Habtamu Mitiku', Zelalem Teklemariam', Bahubali Jinnappa Geddugol ${ }^{1}$, Mahantash Naganuri ${ }^{1}$, Hilina Befikadu ${ }^{2}$ and Eden Tesfaye ${ }^{3}$

\begin{abstract}
Background: Depression among tuberculosis patients, especially in settings with low economic status is common. Screening for depression in all levels of health facilities can identify patients who need support and treatment for depression.

Objective: The aim of this study was to assess the prevalence and associated factors of depression among tuberculosis patients in Eastern Ethiopia.

Methods: An institutional based cross-sectional study was conducted among 403 tuberculosis patients attending in eleven tuberculosis treatment centers in eastern Ethiopia from February to July 2017. Depression was measured using the Patient Health Questionnaire. Data was collected consecutively until the required sample size was obtained. Tuberclusis patients who were under anti tuberculosis treatments for more than one month were included. Data were analyzed with Statistical Package for Social Sciences (SPSS) version 20. Bivariate and multivariate logistic regression models were applied to identify independent factors for dependent variable depression and $P$-values $<0.05$ considered statistically significant.
\end{abstract}

Results: A total of 403 tuberculosis patients were included in the study. The prevalence of depression among tuberculosis patients was $51.9 \%(95 \% \mathrm{Cl}=42.7,62.2 \%)$ with $34.2 \%$ were mild cases. In our logistic regression analysis, odds of developing depression among tuberculosis patients with age less than 25 years were $0.5(50 \%$ protective effect) $[A O R=0.5,95 \% \mathrm{Cl} 0.26-0.99]$ where as patients with a monthly income within the $25^{\text {th }}$ percentile were four times higher odds to have depression [AOR $=3.98,95 \% \mathrm{Cl}: 2.15-7.39]$.

Conclusion: The prevalence of depression was high in this study. Age, low monthly income, the category of patients as "new tuberculosis treatment" and the first 3 months of treatment was associated with depression among tuberculosis patients. Health facilities should integrating mental health services with tuberculosis clinics, especially assessing and treating TB patients for depression, is vital.

Keywords: Depression, MDR/ TB patients, Comorbidity, Stress, Anxiety, Eastern Ethiopia

\footnotetext{
* Correspondence: tamirathenna@gmail.com

${ }^{1}$ Haramaya University, College of Health and Medical Sciences, P.O.Box-235,

Harar, Ethiopia

Full list of author information is available at the end of the article
}

(c) The Author(s). 2019 Open Access This article is distributed under the terms of the Creative Commons Attribution 4.0 International License (http://creativecommons.org/licenses/by/4.0/), which permits unrestricted use, distribution, and reproduction in any medium, provided you give appropriate credit to the original author(s) and the source, provide a link to the Creative Commons license, and indicate if changes were made. The Creative Commons Public Domain Dedication waiver (http://creativecommons.org/publicdomain/zero/1.0/) applies to the data made available in this article, unless otherwise stated. 


\section{Background}

Depressionis a common mental disorder characterized by sadness, loss of interest or pleasure, feelings of guilt or low self-worth, disturbed sleep or appetite, feelings of tiredness, and poor concentration. It can be long-lasting or recurrent, substantially impairing an individual's ability to cope with daily life and can also lead to suicide. At a global level, over 300 million people are estimated to suffer from depression, equivalent to $4.4 \%$ of the world's population. In Ethiopia, a total of 4,480,113 people are estimated to suffer from depression, which is equivalent to $4.7 \%$ the total population [1]. The problem is highly reported from eastern Ethiopia. In one study, the magnitude depression was $14.9 \%$ among the adult population in Harari region, eastern Ethiopia [2].

People with tuberculosis (TB) are often suffer from depression [3, 4].The prevalence of depression among TB patients was reported variable from different studies which is in Nigeria(41.1\%) [5], Cameron (61.1\%) [6] andPakistan (56\%) [7]. InEthiopia, the prevalence depression among TB patients was reported as $43.4 \%$ from Wolaita Sodo, South Ethiopia and 54\% different areasSouth Ethiopia (13).Depression is more common in Multi drug resistant TB patients than other pulmonary TB patients [8].

Depression weakens the psychosocial welfare and results in negative treatment outcomes among TB patients $[9,10]$. It can also negatively affects health-related quality of life of $\mathrm{TB}$ of patients [11]. In addition, TB patients with depressive symptoms have reduce social contact and ignore social responsibilities especially at the stage of coughing that leads to low self-esteem and hopelessness [12].

Several factors were associated with the occurrence of depression among TB patients. Human Immune deficiency Virus (HIV) infection, poor social support and perceived stigma have a higher risk of developing depression among TB patients [13-15]. Other risk factorslike side effects of the drugs, and the financial constraints, Older age, female sex, duration of illness, level of education were also identified $[16,17]$.

There was high prevalence report of TB from presumptive TB patients attending in Ethiopia [18]. However, there is a dearth of information on the comorbidity of depression with tuberculosis in eastern part of Ethiopia. Therefore, this study was tried to assess the magnitude of depression and associated factors among TB patients in eastern Ethiopia.

\section{Methods and materials}

\section{Study setting}

This study was conducted in eight hospitals and three health centers in eastern Ethiopia including Jugal, Hiwot Fana, Karamara, Dil Chora, Sabian, Haramaya, Deder and Chiro hospitals. The health centers were Number One,
Legahare and Amir Nur. The study area has an urban, semi-urban and rural setting with diverse geo-climatic conditions that incorporate low, mid and high lands, and peoples with diverse lifestyles including farmers, agro-pastoralists, pastoralists and urban dwellers.

\section{Study design and period}

An institution-based cross-sectional study was conducted from February to July 2017.

\section{Study population}

Four hundred and three TB patients who were under anti TB treatments for more than one month (after started medication for month) were participated in this study. They have communication problems and had completed treatment were excluded.

\section{Sample size and sampling technique}

The sample size calculated by Open Epi version 3 online software with the following assumptions: population size (for finite population correction factor or fpc) (N) $=1000,000$, hypothesized frequency of outcome factor in the population $(\mathrm{p})=54+/-5$ [17], margin of error $5,95 \%$ $\mathrm{CI}$, and non-response rate $=5 \%$. The final calculated sample size including 5\% non-response rate was $403 \mathrm{~TB}$ patients. Study participants were proportionally allocated for each health facilities according to patients flow by referred the previous year annual reports. TB patients that fulfilled the inclusion criteria were included in the study by consecutively. TB patients that fulfilled the inclusion criteria were selected by consecutive sampling techniques. All eligible TB patients were included to participate in the study until the required sample size obtained.

\section{Study variables}

Presence of depression among $\mathrm{TB}$ patients was our dependent variable. The independent variables included age, sex, residence, religion, ethnicity, marital status, occupational status, educational status, family size, TB treatment duration, type of medication, level of TB treatment and quality of life.

\section{Operational definition}

Percentile of income $=$ (number of people behind of your income /total number of people in study income) $\times 100$. That means $\left(25^{\text {th }}\right.$ percentile can be defined as the lowest income score that is greater than $25 \%$ of the income, for others like $50^{\text {th }}$ and $\left.75^{\text {th }}\right)$.

\section{Data collection}

Data was collected in the local language of the patients, using face-to-face interviews, by 8 psychiatric nurses, in outpatient TB clinics, after informed voluntary and signed consent were obtained. Depression was measured 
using the Patient Health Questionnaire (PHQ-9) and patients with a cut-off value of five or more [19] considered to have a depressive disorder.

\section{Data collection instruments}

Data was collected by structured interview questionnaire and it has two parts. The 1st part contains: sociodemographic characteristics of participants and clinical conditions; the 2nd part contains Patient Health Questionnaire-9 (PHQ-9) depression scale. Depression was assessed using (PHQ-9), questionnairewas prepared in English and translated to local languages (Amharic and Afan Oromo). (PHQ-9) scale has been formally validated in Ethiopia in threedifferent studiesat different setting [20, 21]. Measured using the score from PHQ-9, a nine-item depression-screening instrument that asks about the frequency of symptoms of depression in the past 2 weeks [11, 22]. Response categories of "not at all," "several days," "more than half the days," and "nearly every day" are given a score of 0 to 3 . Summary scores ranged from 0 to 27 . Depression was defined using a score of 10 or higher, a well-validated cut point used in health care settings [22].

\section{Data processing and analysis}

Data entered into Epi Data software version 3.1 and exported to SPSS version 20 for analysis. Descriptive statistics were used to describe the frequency, median, mean and standard deviation. The prevalence of depression was defined as the proportion of those TB patients with depression. Bivariate and multivariate logistic regression models were applied to identify independent factors for dependent variable, depression and $P$-values $<0.05$ considered statistically significant.

\section{Results}

\section{Socio-demographic characteristics}

A total of 403 TB patients participated in this study with response rate of $100 \%$. Median age of the study participants was 30 years with a range of 7-74 yearsand with interquartile range of 18 years. Majority of TB patients were young adults and adolescents in age group less than 35 years (61.5\%), Urban dweller (70.2\%), married (53.6\%) males in sex (59.3\%) and without any formal education and attended only primary schools were (61.3\%) and with family size. 67\% (67\%) of TB patients were newly diagnosed and $70 \% \mathrm{~TB}$ patients were on the treatment for more than 3 months (13.6\%) were HIV positive.The prevalence among MDR-TB patients among TB patients was $24.8 \%$ (Table 1 ).

\section{Magnitude of depression}

The prevalence of depression in people with TB using a cut-off value of five and above was $51.9 \%(95 \% \mathrm{CI}=42.7$, 62.2\%) (Table 2).
Table 1 Socio-demographic characteristics of participants attending TB clinics in health facilities of Eastern Ethiopia, 2017 $(n=403)$

\begin{tabular}{|c|c|c|c|}
\hline Characteristics & & No. & $\%$ \\
\hline \multirow[t]{3}{*}{ Age } & $\leq 24$ & 125 & 31.0 \\
\hline & $25-34$ & 123 & 30.5 \\
\hline & $\geq 35$ & 155 & 38.5 \\
\hline \multirow[t]{2}{*}{ Gender } & Male & 239 & 59.3 \\
\hline & Female & 162 & 40.7 \\
\hline \multirow[t]{2}{*}{ Residence } & Urban & 283 & 70.2 \\
\hline & Rural & 120 & 29.8 \\
\hline \multirow[t]{3}{*}{ Marital status } & Married & 216 & 53.6 \\
\hline & Single & 147 & 36.5 \\
\hline & Separated / Widowed & 40 & 9.9 \\
\hline \multirow[t]{3}{*}{ Educational status } & No formal education & 104 & 25.8 \\
\hline & Primary education & 143 & 35.5 \\
\hline & Secondary and above & 156 & 38.7 \\
\hline \multirow[t]{4}{*}{ Occupations } & Employed & 56 & 13.9 \\
\hline & Private & 131 & 32.5 \\
\hline & Student & 69 & 17.1 \\
\hline & Farmer/Daily laborers & 147 & 36.5 \\
\hline \multirow[t]{3}{*}{ Family size } & $1-2$ & 90 & 22.3 \\
\hline & $3-5$ & 205 & 50.9 \\
\hline & More than 5 & 108 & 26.8 \\
\hline \multirow[t]{3}{*}{ Monthly Income } & $25^{\text {th }}$ percentile & 124 & 30.8 \\
\hline & $50^{\text {th }}$ percentile & 109 & 27.0 \\
\hline & $75^{\text {th }}$ percentile & 170 & 42.2 \\
\hline \multirow[t]{2}{*}{ Level of TB treatment } & New treatment TB & 272 & 67.5 \\
\hline & Retreatment and MDR- TB & 131 & 32.5 \\
\hline \multirow[t]{3}{*}{ TB treatment duration } & $<3$ months & 119 & 29.5 \\
\hline & $3-6$ months & 215 & 53.3 \\
\hline & $>6$ months & 69 & 17.1 \\
\hline
\end{tabular}

Factors associated with depression among TB patients In Multivariate logistic regression analysis, we found out statistically significant associations between dependent and independent variables. Among tuberculosis patients age group less than 25 years, the odds of developing depression were $50 \%$ lower than those older than 35 years (50\% protective effect not to develop depression) [AOR $=0.5,95 \%$ CI 0.26-0.99]. Whereas patients with a monthly income fall in the 25th percentile were four times higher odds to have depression $[\mathrm{AOR}=3.98,95 \%$ CI: 2.15-7.39].Similarly, TB patients within the 25th to 50th percentile were twice as likely to develop depression [1.93, 95th CI 1.08-3.44) (Table 3).

\section{Discussions}

There were very limited studies that assessed the burden of depression among TB patients globally. When compared to the available evidences, magnitude of 
Table 2 Depression scoring scale among in TB patients among Eastern Ethiopia, 2017( $n=403)$

\begin{tabular}{llllr}
\hline Depression Categories & Scoring & Frequency & Percent (\%) & 95\% Confidence Interval \\
\hline No depression & $0-4$ & 194 & 48.1 & {$[43.4,52.9]$} \\
Mild depression & $5-9$ & 138 & 34.2 & {$[30,38.7]$} \\
Moderate depression & $10-14$ & 60 & 14.9 & {$[11.7,18.6]$} \\
Moderately severe depression & $15-19$ & 10 & 2.5 & {$[1,4.2]$} \\
Severe depression & $20-27$ & 1 & 100 & {$[0.0,0.7]$} \\
Total & & 403 & & \\
\hline
\end{tabular}

Table 3 Socio-demographic factors associated with depression among TB patients (AOR with 95\% CI) in eastern Ethiopia from February to July $2017(n=403)$

\begin{tabular}{|c|c|c|c|c|c|c|c|}
\hline \multirow[t]{2}{*}{ Variables } & \multirow[t]{2}{*}{ Categories } & \multicolumn{2}{|c|}{ Depression } & \multirow[t]{2}{*}{ COR $(95 \% \mathrm{Cl})$} & \multirow[t]{2}{*}{ P-Value } & \multirow[t]{2}{*}{ AOR (95\% Cl) } & \multirow[t]{2}{*}{ P-Value } \\
\hline & & $\overline{Y e s}$ & No & & & & \\
\hline \multirow[t]{3}{*}{ Age } & $\leq 24$ & 52 & 73 & $0.45(0.28-0.73)$ & 0.001 & $0.5(0.26-0.99)$ & $0.047^{*}$ \\
\hline & $25-34$ & 62 & 61 & $0.64(0.40-1.04)$ & 0.07 & $0.58(0.335-0.92)$ & $0.05^{*}$ \\
\hline & $\geq 35$ & 95 & 60 & 1 & & 1 & \\
\hline \multirow[t]{2}{*}{ Residence } & Urban & 136 & 147 & $1.68(1.09-2.59)$ & 0.019 & $0.82(0.47-1.43)$ & 0.11 \\
\hline & Rural & 73 & 47 & 1 & & 1 & \\
\hline \multirow[t]{3}{*}{ Marital status } & Married & 125 & 91 & $1.52(0.77-2.99)$ & 0.22 & $2(0.93-4.4)$ & 0.28 \\
\hline & Single & 65 & 82 & $0.88(0.44-1.77)$ & 0.71 & $1.8(0.77-3.49)$ & 0.076 \\
\hline & Separated / Widowed & 19 & 21 & 1 & & 1 & \\
\hline \multirow[t]{3}{*}{ Educational status } & No formal education & 63 & 41 & $1.61(0.98-2.67)$ & 0.06 & $0.69(0.36-1.34)$ & 0.08 \\
\hline & Primary education & 70 & 73 & $1.01(0.64-1,59)$ & 0.97 & $0.81(0.47-1.39)$ & 0.99 \\
\hline & Secondary and above & 76 & 80 & 1 & & 1 & \\
\hline \multirow[t]{4}{*}{ Occupations } & Gov't Employee/ NGO & 29 & 27 & $0.61(0.33-1.13)$ & 0.12 & $1.0(0.46-2.29)$ & 0.15 \\
\hline & Private/merchant & 65 & 66 & $0.56(0.34-0.90)$ & 0.02 & $0.72(0.39-1.31)$ & 0.06 \\
\hline & Student & 21 & 48 & $0.25(0.13-0.46)$ & 0.000 & $0.25(0.11-0.57)$ & $0.04^{*}$ \\
\hline & Farmer/ Housewife/ Daily laborers & 94 & 53 & 1 & & 1 & \\
\hline \multirow[t]{3}{*}{ Family size } & $1-2$ & 40 & 50 & $0.60(0.34-1.04)$ & 0.70 & $0.66(0.34-1.3)$ & 0.12 \\
\hline & $3-5$ & 107 & 98 & $0.81(0.51-1.30)$ & 0.38 & $1.0(0.6-1.8)$ & 0.29 \\
\hline & More than 5 & 62 & 46 & 1 & & 1 & \\
\hline \multirow[t]{3}{*}{ Monthly Income } & 25th percentile & 80 & 44 & $2.42(1.50-3.89)$ & 0.000 & $3.98(2.15-7.39)$ & $0.000^{*}$ \\
\hline & 50th percentile & 56 & 53 & $1.40(0.87-2.28)$ & 0.17 & $1.93(1.08-3.44)$ & $0.026^{*}$ \\
\hline & 75th percentile & 73 & 97 & 1 & & 1 & \\
\hline \multirow[t]{2}{*}{ Level of TB treatment } & New treatment TB & 134 & 138 & $0.73(0.48-1.10)$ & 0.13 & $0.442(0.24-0.83)$ & $0.010^{*}$ \\
\hline & Retreatment/MDR TB & 75 & 56 & 1 & & 1 & \\
\hline \multirow[t]{2}{*}{ HIV status } & HIV positive & 28 & 27 & $0.96(0.54-1.69)$ & 0.87 & $0.99(0.51-1.92)$ & 0.92 \\
\hline & HIV negative & 181 & 167 & 1 & & 1 & \\
\hline \multirow[t]{3}{*}{ TB treatment duration } & $<3$ months & 74 & 45 & $1.60(0.88-2.91)$ & 0.13 & $3.86(1.6-9.3)$ & $0.003^{*}$ \\
\hline & $3-6$ months & 100 & 115 & $0.85(.49-1.45)$ & 0.54 & $1.57(0.72-3.4)$ & 0.58 \\
\hline & $>6$ months & 35 & 34 & 1 & & 1 & \\
\hline
\end{tabular}


depression in our study is comparable to most of sub-Saharan African studies but higher than other settings. This study revealed that $51.9 \%$ of TB patients have probable depression. The finding was comparable with other studies carried out in southern Ethiopia such as $43.4 \%$ in Wolayta zone [23], and 54\% Gurage and Silte zone [24]. It is also similar with other studies conducted sub-Saharan Africa 49.4\% in Angola [25] and 61.1\% findings of the Southwest Region of Cameroon [26]. The prevalence of depression among $\mathrm{TB}$ patients in this study is slightly higher than other similar studies elsewhere like 35\% in India [27], 19\% in Turkey [28].

Severity of depression ranges from a mild form that may not need any medical treatment to the most severe presentations that may require thorough assessment and appropriate management. In this study, almost half of the TB patients were presented with mild to moderate depression while $2.7 \%$ have severe form that requires appropriate treatments. Diagnosing the severity may be important because individuals with advanced forms of depressions may be less likely to adhere to anti-TB drugs which increased risk of drug-resistance [11, 29], poorer quality of life and greater disability [11], lack of adherence to anti-TB treatment and Poor treatment outcomes including death.

In this study, age was found to be one of the risk factors for depression. As similar to another Ethiopian study [17], age less than 35 years was protective for depression among TB patients. This may be at younger age people may engage in different activities to earn money which may increase social interaction and most probably get support from colleagues or relatives. At older age, life in poor countries may be challenging as the habit of saving was low, engagement to economical activities may be stressful beside the challenges of tuberculosis like stigma, discrimination, anti-Tb side effects [30]. These stressful life events and chronicity of tuberculosis were associated with depression in studies conducted in Nigeria and Ethiopia [17, 31].

Low monthly income and depression were significantly associated in this study. Low income in TB patients has the adverse effect on depression. This is similar to a study conducted in China [32], South Africa [33], shanty towns in Lima [34]. In settings with a high burden of tuberculosis, the low income generated will result in difficulty of covering costs for treatment, even if the anti-TB drugs are provided freely. The expenses for additional nutritional needs, transportation and missed work days due to fatigue, chest pain and symptoms of tuberculosis result in lower earnings, and lower earnings will result in psychological distress due to the inability to satisfy the demands of the individual and their household [35].

We found that newly diagnosed patients for TB were associated with depression $(\mathrm{aOR}=0.39(0.21-0.74)$. This is similar to a study in Lima, capital city of Peru, in which depression was highly prevalent among newly diagnosed TB patients [34]. This may be associated with the sign and symptoms of TB especially during the first 3 months in which patients are not familiar with the condition and psychological interventions are almost absent [17]. Another study indicated that being on retreatment for TB $(\mathrm{aOR}=11.2,95 \%$ CI: 5.2-31.1, $P<0.001)$ and having discontinued treatment $(\mathrm{aOR}=8.2,95 \% \mathrm{CI}$ : $1.1-23.3, P<0.05)$ were factors associated with having a higher chance of being depressed [36].

Tuberculosis patients are challenged by mental health problems too. It is difficult to them to lead socially and economically productive life with the health status currently they have due to social isolation [37], depression and an enormous economic burden [38-40]. Therefore, programs designed to control/eliminate tuberculosis in community setting at local, national or international level should also screen and manage depression in addition to financial and social support. For patients admitted to health institutions due to tuberculosis or its complication, it's better to screen for depression and treat it. This may improve treatment outcome and play a positive role in effort to control and eliminate tuberculosis.

Some limitations associated with this study include missing of some important variables not included in PHQ-9 tools such as substance use and smoking which are found to be associated with depression. From co-morbid diseases, only HIV was assessed. On the other hand, the included patients were at any stage of follow-up rather than a specific point in treatment in which true prevalence may be masked by the effect of treatment.

\section{Conclusion}

The burden of depression among tuberculosis patient is high (51.9\%). Financial constraint, older age and new TB patients are risk to develop depression. Depression should be assessed in all TB treatment centres and health professionals should provide appropriate psychological and medical treatment.

\section{Abbreviations \\ Cl: Confidence Interval; DM: Diabetes Mellitus; HIV: Human Immune deficiency Virus; MDR/TB: Multidrug Resistant Tuberculosis; PHQ: Patients Health questionnaire; TB: Tuberculosis; WHO: world health organization}

\section{Acknowledgments}

We thank the study participants for their cooperation in providing the necessary information. The staffs in all health facilities and the data collectors are also acknowledged for their supports during the study period. We would like to thank Haramaya University for financial support. Last, but not least, we thank Dr. Nicole Mohajer for editing the paper.

\section{Author contributions}

TTD, AAR, AA and FW designed the study, acquisition of the data, analysis and interpretation, drafting and critical revision and final approval of the manuscript. FM, HM, ZT, MN and BJG designed the study, acquisition of the data, drafting and critical revision and final approval of the manuscript. HB and ET designed the study, analysis and interpretation, critical revision and final approval of the manuscript. All authors read and approved the final manuscript. 


\section{Consent to publication}

Not applicable

\section{Funding}

This work was supported by Haramaya University Office of Research Affairs by thematic code- HUGR-2016-02-02.

\section{Availability of data and materials}

All data pertaining to the findings are presented in this paper. However, the data can be obtained from the corresponding author at any time on request.

\section{Ethics approval and consent to participate}

Ethical clearance was obtained from the Institutional Health Research and Ethics Review Committee of Haramaya University, College of Health and Medical Sciences. Participants were informed about the purpose, benefits, risks, and the right to participate, refuse and withdraw from the study any time. Throughout the study period, the confidentiality of the data was strictly followed. Informed written and signed consent was obtained from all participants after the participant information sheet was read and/or they read it in their own language. All data collectors were provided information about depression for all participants after collecting data. After data analysis, medical registration numbers (MRN) of TB patients with severe depression were given to health personnel working in TB clinics in order to assess and manage depression. Finally, the finding was presented to all health facilities and responsible individuals to screendepression statues of TB patients in TB clinics.

\section{Competing interests}

All authors declared no conflicts of interest.

\section{Publisher's Note}

Springer Nature remains neutral with regard to jurisdictional claims in published maps and institutional affiliations.

\section{Author details}

${ }^{1}$ Haramaya University, College of Health and Medical Sciences, P.O.Box-235, Harar, Ethiopia. ${ }^{2}$ Haramaya University, College of Social Sciences and Humanities, P.O.Box-138, Dire Dawa, Ethiopia. ${ }^{3}$ Haramaya University, College of Natural and Computational Sciences, P.O.Box-138, Dire Dawa, Ethiopia.

\section{Received: 14 August 2018 Accepted: 28 January 2019}

\section{Published online: 01 March 2019}

\section{References}

1. WHO. Depression and other common mental disorders. In: Global Health estimates Geneva; 2017.

2. Hunduma G, Girma M, Digaffe T, Weldegebreal F, Tola A. Prevalence and determinants of common mental illness among adult residents of Harari regional state Eastern Ethiopia. The Pan African medical journal. 2017;28:262.

3. Doherty AM, Kelly J, McDonald C, O'Dywer AM, Keane J, Cooney J. A review of the interplay between tuberculosis and mental health. Gen Hosp Psychiatry. 2013 Jul-Aug;35(4):398-406.

4. Ambaw F, Mayston R, Hanlon C, Alem A. Burden and presentation of depression among newly diagnosed individuals with TB in primary care settings in Ethiopia. BMC psychiatry. 2017;17(1):57.

5. Ige OM, Lasebikan VO. Prevalence of depression in tuberculosis patients in comparison with non-tuberculosis family contacts visiting the DOTS clinic in a Nigerian tertiary care hospital and its correlation with disease pattern. Ment Health Fam Med. 2011:8(4):235-41.

6. Kehbila J, Ekabe CJ, Aminde LN, Noubiap JJN, Fon PN, Monekosso GL. Prevalence and correlates of depressive symptoms in adult patients with pulmonary tuberculosis in the southwest region of Cameroon. Infect Dis Poverty. 2016;5(51)

7. Amreen and Rizvi N. Frequency of depression and anxiety among tuberculosis patients. Journal of Tuberculosis Research. 2016;4:183-90.

8. Walker IF, Khan AM, Khan AM, Khan NM, Ayub RM, Ghias KN, Walley JD. Depression among multidrug-resistant tuberculosis patients in Punjab, Pakistan: a large cross-sectional study. International Journal of Tuberculosis and Lung Disease. 2018;22(7):773-8.
9. Ugarte-Gil C, Ruiz P, Zamudio C, Canaza L, Otero L, Kruger H, Seas C Association of major depressive episode with negative outcomes of tuberculosis treatment. PLoS One. 2013;8(7):e69514.

10. Koyanagi A, Vancampfort D, Carvalho AF, DeVylder JE, Haro JM, Pizzol D, Veronese N, Stubbs B. Depression comorbid with tuberculosis and its impact on health status: cross-sectional analysis of community-based data from 48 low- and middle-income countries. BMC Med. 2017;15(1):209.

11. Ambaw F, Mayston R, Hanlon C, Medhin G, Alem A. Untreated depression and tuberculosis treatment outcomes, quality of life and disability, Ethiopia. Bull World Health Organ. 2018;96(4):243-55.

12. Morris DM, Quezada L, Bhat P, Moser K, Smith J, Perez H. Social,Economic,and psychological impacts of MDR-TBTreatment in Tijuana, Mexico:APatient'sPerspective. Int J Tuberc Lung Dis. 2013;17(7):954-60.

13. Duko B, Gebeyehu A, Ayano G. Prevalence and correlates of depression and anxiety among patients with tuberculosis at WolaitaSodo University hospital and Sodo health center, WolaitaSodo, South Ethiopia, cross sectional study. BMC Psychiatry. 2015;15

14. Naidoo P, Mwaba K. Helplessness, depression, and social support among people being treated for tuberculosis in South Africa. Soc Behav Pers. 2010; 38(10):1323-34

15. Lee L-Y, Tung H-H, Chen S-C, Fu C-H. Perceived stigma and depression in initially diagnosed pulmonary tuberculosis patients. J Clin Nurs. 2017;26(23-24): 4813-21.

16. Thomas BE, Shanmugam P, Malaisamy M, Ovung S, Suresh C, Subbaraman R, Adinarayanan S, Nagarajan K. Psycho-socio-economic issues challenging multidrug resistant tuberculosis patients: a systematic review. PLoS One. 2016;11:e0147397.

17. Ambaw F, Mayston R, Hanlon C, Alem A. Burden and presentation of depression among newly diagnosed individuals with TB in primary care settings in Ethiopia. BMC Psychiatry. 2017;17(1).

18. Nugussie DA, Mohammed GA, Tefera AT. Prevalence of smear-positive tuberculosis among patients who visited Saint Paul's specialized Hospital in Addis Ababa, Ethiopia. Biomed Res Int. 2017;5.

19. Hanlon C, Medhin G, Selamu M, Breuer E, Worku B, Hailemariam M, Lund C, Prince $M$, Fekadu A. Validity of brief sceening questionnaires to detect depression in primary care in Ethiopia. J Affect Disord. 2015;186:32-9.

20. Woledesenbet MA, Shumet Mekonen S, Sori LM, Abegaz TM. Epidemiology of depression and associated factors among asthma patients in Addis Ababa, Ethiopia. Hindawi Psychiatry Journal. 2017;2018, Article ID 5934872:7.

21. Tilahun H, Awoke N, Geda B, Mesfin F. Depression and associated factors among adult inpatients at public hospitals of Harari regional state, eastern Ethiopia. Hindawi Psychiatry Journal. 2017;2018, Article ID 6743520:6.

22. Kroenke K, Spitzer RL, Williams JBW. The PHQ-9. Validity of a brief depression severity measure. J Gen Intern Med. 2001;16(9):606-13.

23. Duko B, Gebeyehu A, Ayano G. Prevalence and correlates of depression and anxiety among patients with tuberculosis at WolaitaSodo University hospital and Sodo health center, WolaitaSodo, South Ethiopia Cross sectional study. BMC Psychiatry. 2015;15(1):214.

24. Ambaw F, Mayston R, Hanlon C, Alem A. Burden and presentation of depression among newly diagnosed individuals with TB in primary care settings in Ethiopia. BMC Psychiatry. 2017;17

25. Paulo BX, Peixoto B. Emotional distress patients with several types of tuberculosis. A pilot study with patients from the sanatorium Hospital of Huambo. International Journal of Mycobacteriology. 2016;5((Paulo B.X.) Sanatorium Hospital of Huambo, Huambo, Angola):S58.

26. Kehbila J, Ekabe CJ, Aminde LN, Noubiap JJ, Fon PN, Monekosso GL. Prevalence and correlates of depressive symptoms in adult patients with pulmonary tuberculosis in the southwest region of Cameroon. Infect Dis Poverty. 2015:5(1):016-0145.

27. Kumar K, Kumar A, Chandra P, Kansal HM. A study of prevalence of depression and anxiety in patients suffering from tuberculosis. Journal of family medicine and primary care. 2016;5(1):150-3.

28. Aydin 10, Ulusahin A. Depression, anxiety comorbidity, and disability in tuberculosis and chronic obstructive pulmonary disease patients: applicability of GHQ-12. Gen Hosp Psychiatry. 2001;23:77-83.

29. Mukherjee JS, Rich ML, Socci AR, Joseph JK, Viru FA, Shin SS, Furin JJ, Becerra MC, Barry DJ, Kim JY, et al. Programmes and principles in treatment of multidrug-resistant tuberculosis. Lancet. 2004;363(9407):474-81.

30. Thomas BE, Shanmugam P, Malaisamy M, Ovung S, Suresh C, Subbaraman $\mathrm{R}$, Adinarayanan S, Nagarajan K. Psycho-socio-economic issues challenging 
multidrug resistant tuberculosis patients: a systematic review. PLoS One. 2016;11(1):e0147397.

31. Nega Assefa, Aklilu Abrham Roba, Tekabe Abdosh Ahmed, Jelalu Kemal Birmeka, Zergaw ED: Prevalence and factors associated with trachoma among primary school children in Harari region, eastern Ethiopia Ophthalmology Research: An International Journal 2017, 7(3).

32. Chen X, Zhao Y, Xu Y, Zhang H, Sun S, Gao Z, He X. Analyzing the status of depression and anxiety of new registered tuberculosis outpatients and correlations with social support influence factors. National Medical Journal of China. 2016;96(34):2749-53.

33. Peltzer K, Naidoo P, Matseke G, Louw J, McHunu G, Tutshana B. Prevalence of psychological distress and associated factors in tuberculosis patients in public primary care clinics in South Africa. BMC Psychiatry. 2012;12(1).

34. Karlin DM, Evans C, Loiselle C, Zevallos K, Fernandez F, Allen N, Montoya R, Boccia D. Depression is common in TB patients and is associated with treatment abandonment. J Investig Med. 2012;60(1):167.

35. Pachi A, Bratis D, Moussas G, Tselebis A. Psychiatric morbidity and other factors affecting treatment adherence in pulmonary tuberculosis patients. Tuberc Res Treat. 2013;2012:489865.

36. Kehbila J, Ekabe CJ, Aminde LN, Noubiap JJN, Fon PN, Monekosso GL. Prevalence and correlates of depressive symptoms in adult patients with pulmonary tuberculosis in the southwest region of Cameroon. Infectious Diseases of Poverty. 2016;5.

37. Roba AA, Dasa TT, Weldegebrea F, Asfaw A, Mitiku H, Teklemariam Z, Naganuri M, Geddugol BJ, Mesfin F, Befikadu H, et al. Tuberculosis patients are physically challenged and socially isolated: a mixed methods casecontrol study of health related quality of life in eastern Ethiopia. PLoS One. 2018;13(10).

38. Laurence YV, Griffiths UK, Vassall A. Costs to health services and the patient of treating tuberculosis: a systematic literature review. PharmacoEconomics. 2015

39. Fitzpatrick C, Floyd K. A systematic review of the cost and cost effectiveness of treatment for multidrug-resistant tuberculosis. Pharmacoeconomics. 2012; 30(1):63-80.

40. Fuady A, Houweling TAJ, Mansyur M, Richardus JH. Catastrophic total costs in tuberculosisaffected households and their determinants since Indonesia's implementation of universal health coverage. Infectious Diseases of Poverty. 2018;7(3)

Ready to submit your research? Choose BMC and benefit from:

- fast, convenient online submission

- thorough peer review by experienced researchers in your field

- rapid publication on acceptance

- support for research data, including large and complex data types

- gold Open Access which fosters wider collaboration and increased citations

- maximum visibility for your research: over $100 \mathrm{M}$ website views per year

At $\mathrm{BMC}$, research is always in progress.

Learn more biomedcentral.com/submissions 